\title{
Características nutritivas de un ensilado líquido de banano orito (Musa acuminata AA) con tubérculos de taro (Colocasia esculenta (L.) Schott) y su efecto en cerdos de posdestete
}

\author{
Nutritious characteristics of a liquid silage from baby banana \\ (Musa acuminata AA) with taro tubers (Colocasia esculenta (L) Schott) \\ and its effect on post-weaning pigs \\ Willan Caicedo ${ }^{1,2,3}$, Alex Flores ${ }^{1}$
}

\section{Resumen}

El objetivo del estudio fue evaluar el uso del ensilaje líquido de banano orito con tubérculos de taro en la dieta de cerdos en posdestete. En el experimento 1 se preparó un total de 30 microsilos de $1 \mathrm{~kg}$ de capacidad y se determinaron indicadores físicos, microbiológicos, organolépticos y químicos a los 1, 4, 8, 15, 30 y 60 días de fermentación (cinco en cada día). En el experimento 2 se emplearon 60 lechones castrados Landrace $\mathrm{x}$ Duroc x Pietrain de $8.53 \pm 0.28 \mathrm{~kg}$, distribuidos en tres grupos con 20 animales cada uno y alimentados con 0,2 y $4 \%$ de inclusión de ensilaje en la dieta. El ensilado en el día 1 presentó la mayor temperatura $\left(22.56^{\circ} \mathrm{C}\right)$ y $\mathrm{pH}(4.82)$. No hubo presencia de Escherichia coli, Clostridium spp o Salmonella spp. El olor (dulce fermentado), color (verdoso claro) y consistencia (pastosa) del ensilado fue adecuado. Además, presentó un buen tenor de materia seca, materia orgánica, proteína, extractos libres de nitrógeno, energía bruta, energía digestible, energía metabolizable y bajos niveles de cenizas, grasa y fibra. La inclusión de ensilaje líquido de banano orito con tubérculos de taro en la dieta de cerdos en posdestete al 2 y 4\% mejoró el consumo de alimento, ganancia de peso, conversión alimentaria, peso final y redujo la incidencia de diarreas en los animales.

Palabras clave: fermentado líquido, inocuidad alimentaria, lechones. salud intestinal

\section{Abstract}

The aim of this study was to evaluate the use of liquid silage of baby banana with taro tubers in the diet of post-weaning pigs. In experiment 1,30 microsilos of $1 \mathrm{~kg}$ capacity were prepared and physical, microbiological, organoleptic and chemical characteristics

\footnotetext{
${ }^{1}$ Departamento de Ciencias de la Tierra, Universidad Estatal Amazónica, Puyo, Pastaza, Ecuador

${ }^{2}$ Granja Agropecuaria Caicedo, Tarqui, Puyo, Pastaza, Ecuador

${ }^{3}$ E-mail: orlando.caicedo@yahoo.es
}

Recibido: 18 de marzo de 2019

Aceptado para publicación: 12 de diciembre de 2019

Publicado: 31 de marzo de 2020 
were determined at $1,4,8,15,30$ and 60 days of fermentation (five per day). In experiment 2, 60 Landrace $\mathrm{x}$ Duroc $\mathrm{x}$ Pietrain castrated piglets of $8.53 \pm 0.28 \mathrm{~kg}$ were used, distributed in three groups with 20 animals each and fed with 0,2 and $4 \%$ silage inclusion in the diet. The silage on day 1 had the highest temperature $\left(22.56^{\circ} \mathrm{C}\right)$ and $\mathrm{pH}(4.82)$. There was no presence of Escherichia coli, Clostridium spp or Salmonella spp. The odour (fermented sweet), colour (light greenish) and consistency (pasty) of the silage was adequate. In addition, it presented a good content of dry matter, organic matter, protein, nitrogen-free extracts, gross energy, digestible energy, metabolizable energy and low levels of ashes, fat and fibre. The inclusion of 2 and $4 \%$ liquid silage of banana orito with taro tubers in the diet of post-weaning pigs improved feed consumption, bodyweight gain, feed conversion, final body weight and reduced the incidence of diarrhoea in animals.

Key words: fermented liquid, food safety, piglets, intestinal health

\section{INTRODUCCIÓN}

La etapa de posdestete en los lechones es muy estresante, ya que suelen ocurrir trastornos intestinales e inmunológicos con efectos adversos sobre el crecimiento, la salud y la ingesta (Flores et al., 2015). Por otra parte, en esta etapa es común el uso frecuente de antibióticos como promotores de crecimiento, pese a que estos productos pueden presentar un efecto residual en la canal, así como propiciar la resistencia de las bacterias patógenas a dichos antibióticos (Dowarah et $a l ., 2016)$. Desde hace algunos años, se viene trabajando con alimentos líquidos para mejorar el consumo de alimento en lechones recién destetados. En este sentido, los fermentados líquidos tienen un alto contenido de microorganismos beneficiosos dentro de los que se destacan bacterias ácido-lácticas (BAL) y levaduras que ocasionan un efecto benéfico en el tracto gastrointestinal (TGI) de los cerdos a través de la supresión de microorganismo patógenos (Scholten et al., 2001).

En la provincia de Pastaza de la región amazónica ecuatoriana (RAE) existe un gran potencial de recursos alternativos para elaborar fermentados líquidos, entre los que se pueden citar el banano orito (Musa acumi- nata AA), tubérculos de taro (Colocasia esculenta [L] Schott), camote (Ipomoea batatas L), plátano (Musa paradisiaca), caña (Saccharum spp), yuca (Manihot esculenta Crantz) y cacao (Theobroma cacao L), entre otros. La zona posee una superficie agrícola de 96621 ha, de las cuales los cultivares de caña, plátano y banano representa el $5.67 \%$, y la labranza de taro y yuca el 0.61\% (GADMP, 2015). Se conoce que el banano orito y el taro poseen un buen tenor de carbohidratos y que tienen bajo contenido de proteína, fibra y grasa (Adejumo et al., 2013; Odenigbo et al., 2013).

Estos alimentos en estado natural poseen un alto contenido de humedad y tienen poca duración una vez que son cosechados, ya que son atacados por microorganismos descomponedores, de allí que se requiere realizar procesamientos de conservación como el ensilaje líquido para aprovechar sus nutrientes. Este proceso biotecnológico constituye un procedimiento sencillo y adecuado para preservar desechos agroindustriales por tiempo prolongado, utilizándose inóculos de bacterias (Lactobacillus plantarum, L. gasseri, L. acidophilus, L. rhamnosus [casei], Streptococus termofilus, L. bulgaricus, Leuconostoc spp, Pediococcus spp entre otras) en su formulación para generar alimentos para cerdos (Caicedo, 2015). 
El objetivo de este estudio fue valorar los indicadores fisicoquímicos, biológicos y organolépticos de un ensilaje líquido de banano orito verde con tubérculos de taro y su efecto en la alimentación de cerdos en el posdestete.

\section{MATERIALES y Métodos}

\section{Ubicación}

El estudio se realizó en el Laboratorio de Química de la Universidad Estatal Amazónica y en las instalaciones de la Granja Agropecuaria Caicedo ubicadas en el cantón Pastaza, provincia Pastaza, Ecuador. La zona de estudio se encuentra ubicada a 900 msnm, posee un clima semicálido o subtropical húmedo, con precipitaciones anuales entre 4000 y $4500 \mathrm{~mm}$, humedad relativa media de $87 \%$ y temperaturas que fluctúan entre $20 \mathrm{y}$ $28{ }^{\circ} \mathrm{C}$ (INAMHI, 2014).

\section{Ensilado Líquido}

Para la elaboración del ensilado se siguieron las indicaciones de Caicedo (2015). El ensilado líquido se realizó con fruta de banano orito y con tubérculos de taro de desecho que no cumplían con las características mínimas requeridas para el comercio para el consumo humano. Ambos insumos se obtuvieron en el predio de la Granja Agropecuaria Caicedo. Inmediatamente después de la cosecha se lavaron, escurrieron y molieron en forma fresca con un molino mixto provisto de cuchillas y criba de $1 \mathrm{~cm}$ para obtener partículas de tamaño uniforme. Así mismo, se utilizó yogur natural proveniente de la empresa Toni S.A. de la red de distribución Puyo, el cual se transportó en termos de acero inoxidable a $10^{\circ} \mathrm{C}$. El agua potable provino de la red «Junta Parroquial Tarqui» que se distribuye en el sector. El tiempo de traslado de las materias primas hacia las instalaciones de la Granja Agropecuaria Caicedo fluctuó entre 5 y 15 minutos.
Los ingredientes se pesaron en una balanza digital Camry (100 kg de capacidad) y se depositaron en un tanque plástico con 100 $\mathrm{kg}$ de capacidad, a razón de $50 \mathrm{~kg}$ de mezcla. Primero se colocó el banano orito picado $(30 \%)$ con los tubérculos de taro picados $(30 \%)$. En segunda instancia se añadió el yogur natural que estaba a $8{ }^{\circ} \mathrm{C}(1 \%)$ y luego el agua potable (39\%). Las mezclas se homogenizaron manualmente con una paleta de madera durante 15 minutos y a temperatura ambiente $\left(25^{\circ} \mathrm{C}\right)$. Finalmente, se introdujeron en microsilos de polietileno con capacidad para $1 \mathrm{~kg}$, se cerraron y se almacenaron bajo techo y protegidos de la luz solar (Caicedo, 2013). Todos los microsilos se hicieron en forma simultánea y en una sola oportunidad.

\section{Indicadores Físicos y Microbiológicos}

Los indicadores físicos (temperatura y $\mathrm{pH})$ se determinaron en 30 microsilos en los días $1,4,8,15,30$ y 60 del proceso de fermentación, evaluando cinco microsilos por cada medición. La temperatura se comprobó a $20 \mathrm{~cm}$ de profundidad, con un termómetro digital Martini 2012 de precisión $\pm 0.5{ }^{\circ} \mathrm{C}$ (Caicedo, 2013). Para la determinación del $\mathrm{pH}$ se utilizó extracto acuoso formado por una fracción de $25 \mathrm{~g}$ de ensilado y $250 \mathrm{ml}$ de agua destilada (Cherney y Cherney, 2003).

Para los indicadores microbiológicos se tomaron muestras al azar en tres microsilos de los cinco utilizados para la determinación de los indicadores físicos en cada día de conservación. En total se recolectaron 18 muestras, cada una de $200 \mathrm{~g}$ de fermentado, en frascos plásticos trasparentes estériles con capacidad para 250 g. Se realizó el contaje de Escherichia coli, Clostridium spp y Salmonella spp de acuerdo con las indicaciones de la AOAC (2003.01, Ed 20, 2016).

\section{Indicadores Organolépticos y Químicos}

Las características organolépticas (olor, color y consistencia) se determinaron a $\operatorname{los} 4$, $8,15,30$ y 60 d de conservación (Cuadro 1), 
según Caicedo y Valle (2016). Se tomaron muestras al azar en 3 de los 5 microsilos evaluados en los diferentes tiempos de preservación. En total se colectaron 15 muestras de $500 \mathrm{~g}$ cada una de ensilado en tarrinas plásticas de $1 \mathrm{~kg}$ de capacidad.

Para el análisis químico se recolectaron $2 \mathrm{~kg}$ de muestra al azar procedente de los microsilos evaluados al día 8 . Se determinó la materia seca (MS), fibra bruta (FB), cenizas (CENZ), proteína bruta (PB), grasa $(\mathrm{G})$ y extractos libres de nitrógeno (ELN), según los procedimientos de AOAC (2005). El cálculo de la materia orgánica (MO) se hizo restando el porcentaje de cenizas de 100 . La energía bruta (EB) se determinó con una bomba calorimétrica adiabática Parr 1241. La energía digestible (ED) y la energía metabolizable (EM) para cerdos se estimó según Noblet y Pérez (1993).

\section{Animales e Instalaciones}

La investigación se ejecutó según las Directivas para Bienestar Animal de la República de Ecuador (AGROCALIDAD, 2017) y el protocolo experimental de acuerdo con Sakomura y Rostagno (2007). Se emplearon 60 lechones machos castrados, cruce finalizador (Landrace x Duroc x Pietrain), luego del destete (25 días de edad), con un peso medio inicial de $8.53 \pm 0.28 \mathrm{~kg}$. Se utilizaron 20 cerdos por tratamiento, y cada cerdo fue considerado como una unidad experimental.

Los animales se alojaron en jaulas individuales de $0.8 \times 1.0 \mathrm{~m}\left(0.80 \mathrm{~m}^{2}\right)$ durante 28 días. Las jaulas estaban provistas de un comedero tipo tolva y un bebedero tipo chupón, ubicadas en una nave con paredes exteriores de $1.4 \mathrm{~m}$ de altura y piso plástico. La temperatura ambiente promedio en la nave fue de $26^{\circ} \mathrm{C}$. Se determinó el consumo de alimento/ día (CAD), el peso inicial (PI) y peso final (PF) la ganancia de peso/día (GPD), la conversión alimentaria (CA), y la incidencia de diarreas (ID) según Flores et al. (2015). El pasaje de los animales se hizo cada siete días, con el empleo de una balanza digital Camry TCS150 con capacidad para $150 \mathrm{~kg}$.

\section{Manejo de la Alimentación}

Luego de los estudios de la dinámica de los indicadores físicos, químicos, microbiológicos y organolépticos del ensilaje, el alimento ensilado para los cerdos se preparó cada 8 días en tres tanques plásticos con capacidad para $150 \mathrm{~kg}$ cada uno. En cada tanque se dispuso $100 \mathrm{~kg}$ de mezcla, según metodología descrita anteriormente.

Se consideró 0,2 y $4 \%$ de inclusión de ensilado en la dieta, estableciendo los tratamientos T0, T2 y T4, respectivamente. Las dietas fueron formuladas siguiendo los procedimientos de la NRC (2012) (Cuadro 2). El alimento se suministró dos veces al día: 08:00 y 15:00 horas, dividido en partes iguales. El agua para bebida se dispuso a voluntad.

\section{Diseño Experimental}

Los resultados de los indicadores físi$\cos$, microbiológicos, organolépticos y químicos se presentaron como media y desviación estándar. Los datos de los indicadores productivos se contrastaron a través de análisis de varianza y la comparación de medias se hizo con la dócima de Duncan $(\mathrm{p}<0.05)$. Todos los análisis fueron realizados con el programa estadístico Infostat (Di Rienzo et al., 2012).

\section{Resultados}

No se evidenciaron síntomas de descomposición del material al momento de la apertura de los microsilos. La temperatura más alta del ensilado fue $\left(22.56^{\circ} \mathrm{C}\right)$ fue en el día 1 (Figura 1), reduciéndose en el día 4 , para mantenerse hasta el día 60 de la investigación. 
Cuadro 1. Descriptores para la valoración organoléptica de ensilajes de subproductos agrícolas

\begin{tabular}{llll}
\hline Atributo & Bueno (1) & Regular (2) & Malo (3) \\
\hline Olor & Dulce fermentado & Ácido suave & Pútrido \\
Color & $\begin{array}{l}\text { Gris claro, verdoso claro, } \\
\text { café amarillento }\end{array}$ & $\begin{array}{l}\text { Gris oscuro, verdoso } \\
\text { oscuro, café oscuro }\end{array}$ & Negruzco \\
Consistencia & Semidura, pastosa & Semilíquida & Líquida \\
\hline
\end{tabular}

Fuente: Caicedo y Valle (2016)

Cuadro 2. Composición y aporte de las dietas experimentales (\% Base seca)

\begin{tabular}{lccc}
\hline \multirow{2}{*}{ Materias primas } & \multicolumn{3}{c}{ Niveles de inclusión de ensilado, \% } \\
\cline { 2 - 4 } & 0 & 2 & 4 \\
\hline Maíz amarillo precocido & 49.984 & 42.643 & 40.39 \\
Leche integral en polvo & 2.000 & 2.000 & 2.000 \\
Harina de soya liofilizada & 18.001 & 23.342 & 23.60 \\
Aceite vegetal & 1.535 & 1.535 & 1.535 \\
Harina de trigo & 10.00 & 10.00 & 10.00 \\
Germen de trigo & 10.00 & 10.00 & 10.00 \\
Carbonato de calcio & 0.401 & 0.401 & 0.401 \\
Fosfato monodicálcico & 2.331 & 2.331 & 2.331 \\
Premezcla vit. mineral cerdos ${ }^{1}$ & 0.400 & 0.400 & 0.400 \\
DL-metionina 99\% & 0.283 & 0.283 & 0.283 \\
L-lisina HCL 78\% & 0.663 & 0.663 & 0.663 \\
Cloruro de colina 60\% & 0.200 & 0.200 & 0.200 \\
Antimicótico & 0.050 & 0.050 & 0.050 \\
Cloruro de sodio & 0.500 & 0.500 & 0.500 \\
Almidón & 3.652 & 3.652 & 3.652 \\
Ensilaje líquido & - & 2.000 & 4.000 \\
Aporte de nutrientes & & & \\
Energía metabolizable & & 3270 & 3270 \\
$\quad$ (kcal.kg.MS ${ }^{-1}$ ) & 3240 & & \\
Proteína cruda, \% & & 19.24 & 19.24 \\
Fibra cruda, \% & 19.24 & 2.73 & 2.73 \\
\hline
\end{tabular}

${ }^{1}$ Premezcla suministrada (por kg de dieta seca): Vitaminas; A 1500 UI, D3 300 UI, E 37.5 mg, K 2.5 mg, B1 $1.5 \mathrm{mg}, \mathrm{B} 26.25 \mathrm{mg}, \mathrm{B} 63 \mathrm{mg}, \mathrm{B} 1237.5 \mathrm{~g}$, pantotenato de calcio $25 \mathrm{mg}$, ácido fólico $0.5 \mathrm{mg}$, niacina $30 \mathrm{mg}$, biotina $75 \mathrm{~g}$. Minerales: cobalto $0.5 \mathrm{mg}$ (como heptahidrato de sulfato de cobalto), cobre $25 \mathrm{mg}$ (como sulfato de cobre pentahidratado), $1.25 \mathrm{mg}$ de yodo (como yodo potásico), $150 \mathrm{mg}$ de hierro (como sulfato ferroso), $100 \mathrm{mg}$ de manganeso (como óxido de manganeso), selenio $0.5 \mathrm{mg}$ (como selenito de sodio), zinc $0.25 \mathrm{mg}$ (como óxido de zinc)

${ }^{2}$ Calculados según NRC (2012) y/o determinados 


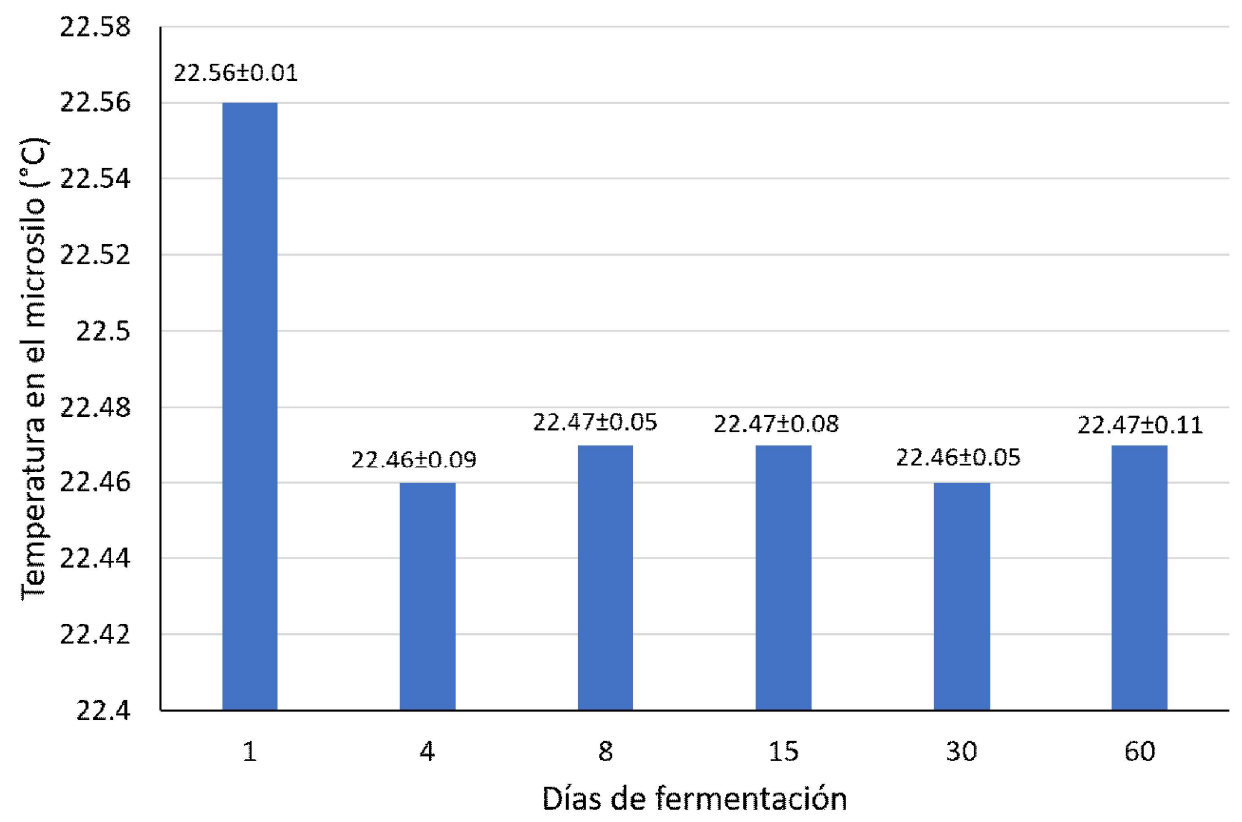

Figura 1. Conducta de la temperatura $\left({ }^{\circ} \mathrm{C}\right)$ en un ensilado líquido de banano orito con tubérculos de taro durante los primeros 60 días de conservación (media \pm desviación estándar)

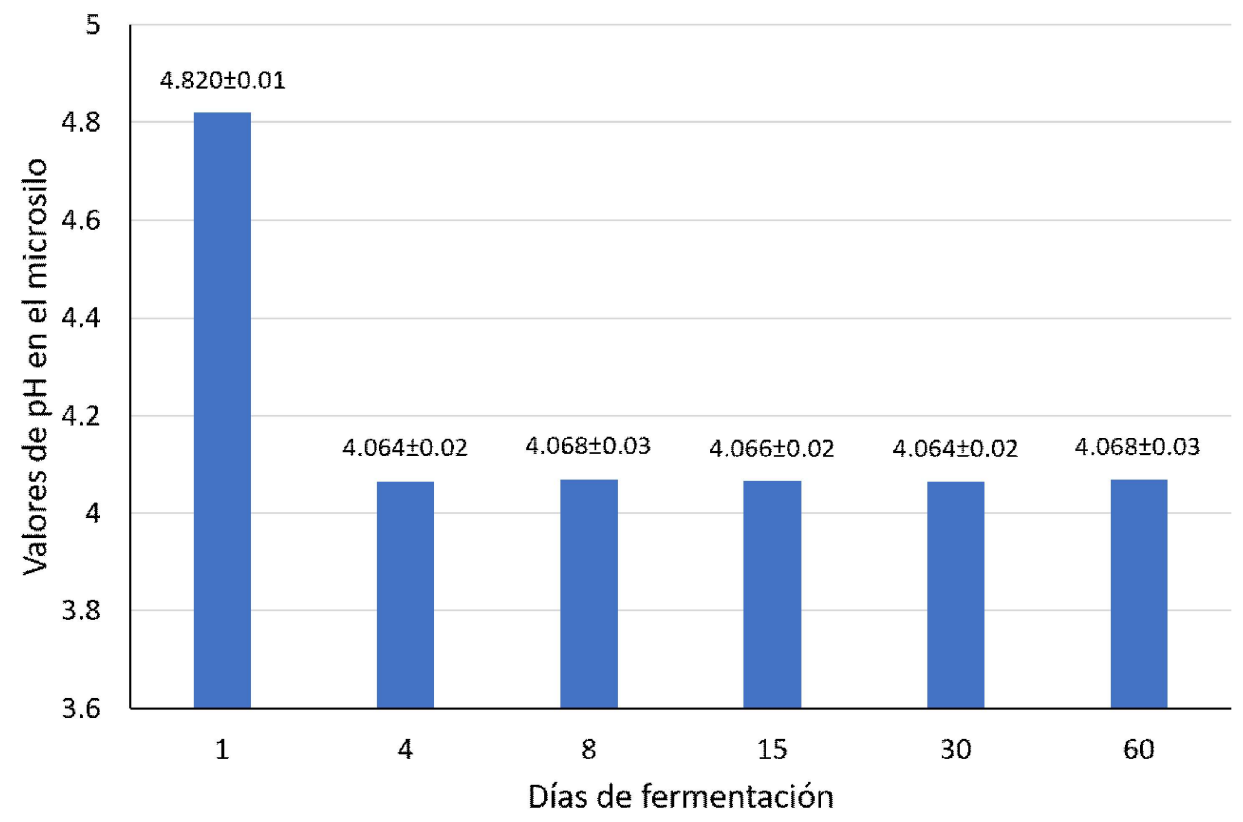

Figura 2. Comportamiento del $\mathrm{pH}$ en un ensilado líquido de banano orito con tubérculos de taro durante los primeros 60 días de conservación (media \pm desviación estándar) 
Cuadro 3. Composición química de un ensilado líquido de banano orito con tubérculos de taro en base seca

\begin{tabular}{lcc}
\hline Nutrientes & Media & D.E. \\
\hline MS, \% & 20.41 & 0.01 \\
MO, \% & 95.62 & 0.24 \\
PB, \% & 5.69 & 0.62 \\
FB, \% & 1.20 & 0.65 \\
G, \% & 1.36 & 0.34 \\
CENZ, \% & 4.38 & 0.24 \\
ELN, \% & 80.32 & 0.01 \\
EB, kcal kg MS & 3919.00 & 1.41 \\
ED cerdos, & 3391.56 & 1.50 \\
$\quad$ kcal kg MS & & \\
EM cerdos, & 3262.12 & 1.68 \\
$\quad$ kcal kg MS & & \\
\hline
\end{tabular}

La dinámica del $\mathrm{pH}$ del ensilado líquido de banano orito con tubérculos de taro se muestra en la Figura 2. El valor de pH más alto (4.82) se obtuvo al inicio de la fermentación (día 1), manteniéndose estable entre los días 4 y 60.

En el recuento de microorganismos no se encontró Escherichia coli, Clostridium spp ni Salmonella spp. Tampoco se evidenciaron cambios en las características organolépticas del ensilado, siendo aptas $(100 \%)$ con relación a olor (dulce fermentado), color (verdoso claro) y consistencia (pastosa).

La composición química del ensilado se muestra en el Cuadro 3. El ensilado presentó un contenido aceptable de MS, MO, PB, ELN, EB, ED, EM y bajos niveles de CENZ, G y FB.

Los animales que consumieron los tratamientos que se incluyeron ensilado líquido al 2 y $4 \%$ presentaron el mejor consumo, ganancia de peso, conversión alimentaria, peso final y menor incidencia de diarreas, siendo diferentes de $\mathrm{T} 0$ ( $\mathrm{p}<0.05$; Cuadro 4).

\section{Discusión}

El ensilaje de banano con tubérculos de taro presentó la mayor temperatura en el día 1 del proceso de fermentación. Diversos estudios indican que en el inicio del proceso de ensilaje existe una fase aeróbica que dura pocas horas, donde el oxígeno atmosférico presente en el material vegetal disminuye rápidamente debido a la respiración del material vegetal y por la presencia de microorganismos aeróbicos y aeróbicos facultativos

Cuadro 4. Indicadores productivos de cerdos en fase de posdestete, alimentados con o sin inclusión de ensilaje líquido de banano orito con tubérculos de taro

\begin{tabular}{lccccc}
\hline \multirow{2}{*}{ Variables } & \multicolumn{3}{c}{ Niveles de inclusión de ensilado } & \multirow{2}{*}{ EE } & \multirow{2}{*}{ Valor de $\mathrm{p}$} \\
\cline { 2 - 4 } & $\mathrm{T} 0$ & $\mathrm{~T} 2$ & $\mathrm{~T} 4$ & & \\
\hline Peso inicial, $\mathrm{kg}$ & 8.53 & 8.53 & 8.53 & 0.06 & $\mathrm{p}=0.9999$ \\
Consumo día, $\mathrm{kg}$ & $0.53^{\mathrm{b}}$ & $0.74^{\mathrm{a}}$ & $0.75^{\mathrm{a}}$ & 0.01 & $\mathrm{p}<0.0001$ \\
Ganancia de peso diario, $\mathrm{kg}$ & $0.320^{\mathrm{b}}$ & $0.470^{\mathrm{a}}$ & $0.490^{\mathrm{a}}$ & 0.01 & $\mathrm{p}<0.0026$ \\
Conversión alimentaria, $\mathrm{kg} / \mathrm{kg}$ & $1.69^{\mathrm{b}}$ & $1.58^{\mathrm{a}}$ & $1.53^{\mathrm{a}}$ & 0.03 & $\mathrm{p}<0.0003$ \\
Peso final, kg & $17.37^{\mathrm{b}}$ & $21.80^{\mathrm{a}}$ & $22.29^{\mathrm{a}}$ & 0.21 & $\mathrm{p}<0.0001$ \\
Incidencia de diarreas, \% & $56.15^{\mathrm{b}}$ & $10.38^{\mathrm{a}}$ & $10.00^{\mathrm{a}}$ & 2.41 & $\mathrm{p}<0.0001$ \\
\hline
\end{tabular}

$a, b, c$ Medias con letras distintas en la misma fila son estadísticamente diferentes $(p<0.05)$

T0, T2, T4: 0, 2, y $4 \%$ de inclusión de ensilaje en la dieta, respectivamente 
(hongos, levaduras y enterobacterias), generándose una significante actividad de enzimas vegetales (proteasas, carbohidrasas) (Zahiroddini et al., 2004; Duniere et al., 2015). Al mismo tiempo, durante el proceso respiratorio en los silos se produce calor, agua y dióxido de carbono, causando una elevación de la temperatura (Blanco-Valdés et al., 2016).

La temperatura se mostró estable entre el día 4 y 60 del estudio, posiblemente debido a la inoculación con bacterias ácido lácticas (BAL) del yogur natural. Al respecto, la inoculación con BAL del material a conservar juega un papel clave para el éxito o el fracaso del proceso de ensilaje (Granados-Marín et al., 2014; Espinoza et al., 2017; Borreani et al., 2018). La inoculación con bacterias homolácticas (Pediococcus pentosaceus, Lactobacillus plantarum) promueven una rápida disminución del $\mathrm{pH}$ del medio. Lactobacillus buchneri produce ácido acético y mejora la estabilidad aeróbica del ensilaje. Estas bacterias, así como $L$. buchneri son inoculantes con capacidad de producir enzimas fibrolíticas que mejoran la digestibilidad del alimento ensilado (Cubero et al., 2010; Reich y Kung, 2010; Schmidt y Kung, 2010; Addah et al., 2012).

La escasa variación en la temperatura se atribuye a que no hubo actividad de microorganismos descomponedores (Penicillium, Fusarium, Aspergillus, Mucor, Byssochlamys, Absidia, Arthrinium, Geotrichum, Monascus, Scopulariopsis, Trichoderma, Clostridium) (Jonsson et al., 1990; Nout et al., 1993; Muck, 2010; Lima et al., 2017). Así también, este rango de temperatura permite mantener un equilibrio en el $\mathrm{pH}$ con valores cercanos a 4 , y producir un ensilaje líquido de óptima calidad nutritiva para los animales (Caicedo, 2013). Por otro lado, cuando hay cambios bruscos en la temperatura de los silos se perturba la acción de las BAL (Song et al., 2014), pudiéndose generar pérdidas importantes de MS por el agotamiento de las fracciones de hidratos de carbono y ácidos orgánicos digestibles del material ensilado (Borreani et al., 2007; Bernardes et al., 2012).
El mayor valor de $\mathrm{pH}$ en el ensilado se evidenció en el día 1, dado que la actividad de las BAL es reducida al inicio del proceso fermentativo; así mismo, el cambio de $\mathrm{pH}$ depende de la cantidad del inóculo y de carbohidratos solubles que se utilicen en los ensilados para que la población microbiana benéfica se desarrolle rápidamente y se reduzca el $\mathrm{pH}$ para aumentar las concentraciones de lactato y acetato en el ensilaje (McEniry et al., 2008; Ogiy et al., 2015; Graf et al., 2016). La estabilización del $\mathrm{pH}$ a partir del día 4 se puede atribuir a la acción de las BAL que lograron colonizarse y fermentaron los carbohidratos hidrosolubles del banano y del taro produciendo ácido láctico y en menor cuantía ácido acético. En este sentido, Li y Nishino (2011) señalan que para mejorar la fermentación del ácido láctico y acético en los silos se deben utilizar inóculos de Lactobacillus, Enterococcus y Pediococcus. $\mathrm{Al}$ producirse estos ácidos, el $\mathrm{pH}$ del material ensilado baja a un nivel que inhibe la presencia de microorganismos que inducen la putrefacción.

Se reporta que la inoculación con $L$. plantarum a concentraciones de $3.0 \times 10^{12} \mathrm{y}$ $6.0 \times 10^{11} \mathrm{UFC} / \mathrm{ml}$ y con Lactobacillus plantarum CCM 4000, L. fermentum LF2 y Enterococcus faecium CCM 4231 en una concentración de $1.0 \times 10^{9} \mathrm{UFC} / \mathrm{ml}$ a las 12 horas se genera un $\mathrm{pH}$ menor a 4.2 (Jalè et al., 2009; Jurado-Gámez et al., 2013). Al respecto, Nkosi y Meeske (2010), Jatkauskas et al. (2018) y Muck et al. (2018) mencionan que la estabilización del $\mathrm{pH}$ dentro de las primeras horas de iniciado el proceso de fermentación permite minimizar las concentraciones de ácido butírico, nitrógeno amoniacal y alcohol en los silos. Además, un bajo $\mathrm{pH}$ en los silos favorece la hidrolisis de los polisacáridos del material vegetal para las BAL (Li et al., 2016).

En todos los días de estudio hubo ausencia de Escherichia coli, Clostridium spp y Salmonella spp en los silos. Las BAL conservan los alimentos a través de la inhibición de microorganismos patógenos y descom- 
ponedores por medio de sus productos de fermentación (ácidos láctico y acético, peróxido de hidrógeno, diacetilo, bacteriocinas y otros productos concebidos por medio de lactoperoxidasa sobre el peróxido de hidrógeno y tiocianato) (Shirai et al., 1996; Zhang et al., 2018).

El ensilado mostró características organolépticas idóneas durante el estudio. En este sentido, la mayoría de las BAL se usan en la industria alimentaria para elaborar productos fermentados y como complementos alimenticios que mejoran la salud del hombre y animales (Ramírez et al., 2011). Así también, existe un deterioro más lento del ensilado luego de su exposición al aire (Rodríguez et al., 2016). Las BAL (Lactococcus, Lactobacillus, Enterococcus, Streptococcus, Leuconostoc y Pediococcus) desempeñan un papel importante en la industria alimentaria por su contribución con el sabor, olor, textura, características sensoriales, propiedades terapéuticas y el valor nutricional de los productos alimentarios. Entre sus metabolitos se incluyen vitaminas, ácidos orgánicos polisacáridos, sustancias persevantes y endulzantes (Parra, 2010).

El ensilado presentó un contenido aceptable de MS, MO, PB, ELN, EB, ED, EM y bajos niveles de CENZ, G y FB. Resultados superiores en cuanto a MS (24.63-33.75\%) y PB (9.66-11.15\%) fueron reportados por García et al. (2015) en un ensilado líquido (de 8 días de fermentación) compuesto por $60 \%$ de tubérculos de camote (Ipomoea batata) picados y, una mezcla de $40 \%$ entre crema de Saccharomyces cerevisiae, vinaza concentrada y melaza de caña de azúcar tipo B. El mayor valor de MS y PB registrado por estos autores pudiera deberse a que la melaza de caña de azúcar realizó un aporte significativo de materia seca (FEEDNA, 2019) y la crema de $S$. cerevisiae contribuyó con el incremento de la PB del ensilado (Morales 2007; Suárez-Machín et al., 2016).
Por otro lado, resultados similares con relación al tenor de MO, CENZ, G, FB, ELN, EB, ED y EM fueron reportados por Caicedo (2015) y Caicedo et al. (2015) en ensilados líquidos de tubérculos de taro tratados con yogur natural, suero de leche y melaza. En este sentido, Lezcano et al. (2015) destacan que los ensilados líquidos de recursos alternativos tienen un buen contenido energético, así como bajos niveles de CENZ, G y FB, lo cual es satisfactorio desde el punto de vista para la alimentación de porcinos en la etapa de posdestete (Bertechini, 2013).

Los animales que se alimentaron con las dietas T2 y T4 presentaron el mejor consumo, ganancia de peso, conversión alimentaria, peso final, y menor incidencia de diarreas en los lechones. En este sentido, se observa la conveniencia de utilizar alimentos líquidos fermentados para minimizar el uso de antibióticos en la producción porcina (PlumedFerrer y Von Wright, 2009). La fermentación líquida por la acción de las BAL y levaduras ha demostrado mejorar la calidad de los piensos y ser beneficioso para la salud de los animales, debido probablemente a la acción del ácido láctico y ácido acético en el estómago de los cerdos, los cuales reducen el $\mathrm{pH}$ intestinal y actúan contra las bacterias patógenas del intestino (Van Winsen et al., 2001; Scholten et al., 2002; Plumed-Ferrer et al., 2005).

En otros estudios referentes a ensilados líquidos de yuca (Manihot esculenta) producidos en Cuba y Brasil y suministrados a cerdos de crecimiento se lograron mejoras en el aprovechamiento de nutrientes y de los indicadores del comportamiento productivo de los animales; de hecho, en esta etapa lograron reemplazar completamente al maíz de la dieta (Lezcano et al., 2014; Araújo et al., 2016). Esto se atribuye a que los alimentos fermentados liberan con mayor facilidad sus nutrientes producto de la acción enzimática de los microorganismos beneficiosos que se desarrollan en el medio (levaduras y BAL) (Silva et al., 2008; Silva et al., 2010; Taysayavong, 2018). 
En síntesis, existen varios estudios que demuestran que el uso de cepas de BAL en los alimentos mejoran el consumo, eficiencia en la conversión de nutrientes, utilización de nutrientes, microbiota intestinal benéfica, salud intestinal, sistema inmunitario, producción de sustancias antimicrobianas, patrones de resistencia a los antibióticos (Wang et al., 2012; Hou et al., 2015) y, previenen la colonización intestinal de patógenos entéricos (Lee et al., 2012).

\section{Conclusión}

La inclusión de ensilaje líquido de banano orito con tubérculos de taro en la dieta de cerdos en posdestete al 2 y $4 \%$ mejoró el consumo de alimento, ganancia de peso, conversión alimentaria, peso final y redujo la incidencia de diarreas en los animales.

\section{Agradecimientos}

Se agradece al personal técnico de la Granja Agropecuaria Caicedo y del Laboratorio de Química de la Universidad Estatal Amazónica por el apoyo en esta investigación.

\section{Literatura Citada}

1. [AGROCALIDAD] Agencia Ecuatoriana de Aseguramiento de la Calidad del Agro. 2017. Manual de aplicabilidad de buenas prácticas porcícolas. Quito, Ecuador. 127 p. [Internet]. Disponible en: http:// www.agrocalidad.gob.ec/wp-content/ uploads/pdf/Guia-BPA-publicaciones/ 2017/enero/manual-buenas-practicasporcicolas-24-01-2017.pdf

2. [AOAC] Association of Official Agricultural Chemists. 2005. Official methods of analysis. $18^{\text {th }}$ ed. Gaithersburg, MD, USA. AOAC
3. [AOAC] Association of Official Agricultural Chemists. 2016. Official methods of analysis. 2003.01, Ed 20, 2016. $20^{\text {th }}$ ed. Rockville, MD, USA: AOAC. [Internet]. Available in: http:// www.directtextbook.com/isbn/ 9780935584875

4. Addah W, Baah J, Groenewegen P, Okine EK, McAllister TA. 2011. Comparison of the fermentation characteristics, aerobic stability and nutritive value of barley and corn silages ensiled with or without a mixed bacterial inoculant. Can J Anim Sci 91: 133-146. doi: 10.4141/CJAS10071

5. Adejumo IO, Babalola TO, Alabi OO. 2013. Colocasia esculenta (L) Schott as an alternative energy source in animal nutrition. Br J Appl Sci Technol 3: 1276-1285.

6. Araújo D, Amorim A, Saleh M, Curcelli F, Perdigon P, Bicudo S, Berto D. 2016. Nutritional evaluation of integral cassava root silages for growing pigs. Anim Nutr 2: 149-153. doi: 10.1016/ j.aninu.2016.04.006

7. Bernardes TF, Nussio LG, Amaral RC. 2012. Top spoilage losses in maize silage sealed with plastic films with different permeabilities to oxygen. Grass Forage Sci 67: 34-42. doi: $10.1111 / \mathrm{j} .1365-$ 2494.2011.00823.x

8. Bertechini AG. 2013. Nutrição de monogástricos. $2^{\circ}$ ed rev. MG, Brasil: UFLA. 373 p.

9. Blanco-Valdes Y, Durañona H, Acosta R. 2016. Efecto de la temperatura y la humedad en la conservación de granos de maíz en silos metálicos refrigerados. Cultivos Tropicales 37: 105-114. doi: 10.13140/RG.2.2.13900.21127

10. Borreani G, Tabacco E, Cavallarin L. 2007. A new oxygen barrier film reduces aerobic deterioration in farm-scale corn silage. J Dairy Sci 90: 4701-4706. doi: 10.3168/jds.2007-0310

11. Borreani G, Tabacco E, Schmidt RJ, Holmes BJ, Mucks RE. 2018. Silage review: factors affecting dry matter and 
quality losses in silages. J Dairy Sci 101: 3952-3979. doi: 10.3168/jds.2017-13837

12. Caicedo WO. 2013. Potencial nutritivo del ensilado de tubérculos de papa china (Colocasia esculenta (L) Schott) para la alimentación de cerdos. Tesis de Maestría. Bayamo, Cuba: Univ. de Granma. $60 \mathrm{p}$.

13. Caicedo WO. 2015. Valoración nutritiva del ensilado de tubérculos de papa china (Colocasia esculenta (L) Schott) y su uso en la alimentación de cerdos en crecimiento ceba. Tesis Doctoral. Bayamo, Cuba: Univ. de Granma. 100 p.

14. Caicedo W, Rodríguez $R$, Lezcano $P$, Ly J, Valle S, Flores L, Ferreira FNA. 2015. Chemical composition and in vitro digestibility of silages of taro (Colocasia esculenta (L) Schott) tubers for feeding pigs. Cuban J Agr Sci 49: 59-64.

15. Caicedo W, Valle $S$. 2016. Ensilaje líquido de subproductos agrícolas para la alimentación animal. Alemania: Académica Española. 60 p.

16. Cherney JH, Cherney DJR. 2003. Assessing silage quality. In: Buxton DR, Muck RE, Harrison JH (eds). Silage science and technology, Wisconsin, USA: American Society of Agronomy. p 141-198.

17. Cubero J, Rojas A, Wing R. 2010. Uso del inóculo microbial elaborado en finca en ensilaje de maíz (Zea mays) valor nutricional y fermentativo. Agron Costarric 34: 237-250.

18. Di Rienzo JA, Casanoves F, Balzarini MG, González, L, Robledo CW. 2012. InfoStat v. 2012. [Internet]. Available in: http://www.infostat.com.ar/

19. Dowarah R, Verma AK, Agarwal N. 2016. The use of Lactobacillus as an alternative of antibiotic growth promoters in pigs: a review. Anim Nutr 3: 1-6. doi: 10.1016/j.aninu.2016.11.002

20. Duniere L, Jin L, Smiley B, Qi M, Rutherford W, Wang Y, McAllister T. 2015. Impact of adding Saccharomyces strains on fermentation, aerobic stability, nutritive value, and select lactobacilli populations in corn silage. J Anim Sci 93: 2322-2335. doi: 10.2527/jas2014-8287

21. Espinoza I, Montenegro L, Sánchez A, Romero M, Medina M, García A. 2017. Inoculantes microbianos sobre la composición bromatológica y estabilidad aeróbica de ensilado de maíz forrajero (Zea mays) y cáscara de maracuyá (Passiûora edulis). Cienc Tecn UTEQ 10: 63-68. doi: 10.18779/cyt.v10i2.168

22. [FEDNA] Fundación Española para el Desarrollo de la Nutrición Animal. 2019. Melazas de caña. [Internet]. Available in: http://www.fundacionfedna.org/ingredientes para piensos/ melazas-de-ca $\% \mathrm{C} 3 \% \mathrm{~B} 1 \mathrm{a}$

23. Flores L, Elías A, Medina Y, Proaño F, Granizo G, López S, Caicedo W. 2015. Increasing doses of a microbial preparation in the health and productive performance of post-weaning pigs Cuban J Agr Sci 49: 367-376.

24. [GADMP] Gobierno Autónomo Descentralizado Municipal de Pastaza. 2015. Plan de Desarrollo y Ordenamiento Territorial del Cantón Pastaza 20152020. Áreas Agropecuarias, Pastaza, Ecuador, 263 p.

25. García Y, Sosa D, Boucourt R, Scull I. 2015. Chemical characterization of an ensiled food for pigs. Cuban J Agr Sci 49: 91-92.

26. Graf K, Ulrich A, Idler C, Klocke M. 2016. Bacterial community dynamics during ensiling of perennial ryegrass at two compaction levels monitored by terminal restriction fragment length polymorphism. J Appl Microbiol 120: 1479-1491. doi: 10.1111/jam.13114

27. Granados-Marín C, Ching-Jones R, Rojas-Bourrillón, A. 2014. Ensilaje de pasto estrella africana (Cynodon nlemfuensis) con la adición de melaza, suero de leche e inóculos microbiales. Cuadernos de Investigación UNED 6: 47-56.

28. Hou C, Zeng X, Yang F, Liu H, Qiao $S$. 2015. Study and use of the probiotic Lactobacillus reuteri in pigs: a review. J Anim Sci Biotechnol 6: 14. doi: 10.1186/ s40104-015-0014-3 
29. [INAMHI] Instituto Nacional de Meteorología e Hidrología. 2014. Anuario meteorológico. Quito, Ecuador. 28 p. [Internet]. Available in: http:// www.serviciometeorologico.gob.ec/wpcontent/uploads/anuarios/ meteorologicos/Am\%202011.pdf

30. Jalè D, Lauková A, Simonová M, Váradyová Z, Homolka P. 2009. The use of bacterial inoculants for grass silage: their effects on nutrient composition and fermentation parameters in grass silages. Czech J Anim Sci 54: 84-91. doi: 10.17221/1665-CJAS

31. Jatkauskas J, Vrotniakienë V, Stoðkus R. 2018. Variations in fermentation, bacterial population and aerobic stability in maize silage. Zemdirbyste 105:377-382.

32. Jonsson A, Lindberg H, Sundås $S$, Lingvall P, Lindgren S. 1990. Effect of additives on the quality of big-bale silage. Anim Feed Sci Tech 31: 139-155. doi: 10.1016/0377-8401(90)90120-W

33. Jurado-Gámez H, Ramírez C, Aguirre D. 2013. Cinética de fermentación de Lactobacillus plantarum en un medio de cultivo enriquecido como potencial probiótico. Vet Zootec 7: 37-53.

34. Lee JH, Valeriano VD, Shin YR, Chae JP, Kim GB, Ham JS, Chun J, Kang DK. 2012. Genome sequence of Lactobacillus mucosae LM1 isolated from piglet feces. J Bacteriol 194: 4766. doi: 10.1128/JB.01011-12

35. Lezcano P, Berto DA, Bicudo SJ, Curcelli F, González, Paldivié M. 2014. Yuca ensilada como fuente de energía para cerdos en crecimiento. Avances Invest Agropec 18: 41-47.

36. Lezcano P, Vázquez A, Bolaños $A, P i-$ loto JL, Martínez M, Rodríguez $Y$. 2015. Ensilado de alimentos alternativos, de origen cubano, una alternativa técnica, económica y ambiental para la producción de carne de cerdo. Cuban J Agr Sci 49: 65-68.

37. Li X, Xu W, Yang J, Zhao H, Pan C, Ding $X$, Zhang Y. 2016. Effects of applying lactic acid bacteria to the fermentation on a mixture of corn steep liquor and air-dried rice straw. Anim Nutr 2: 229-233. doi: 10.1016/j.aninu.2016.04.003

38. Li Y, Nishino N. 2011. Bacterial and fungal communities of wilted Italian ryegrass silage inoculated with and without Lactobacillus rhamnosus or Lactobacillus buchneri. Appl Microbiol 52: 314-321. doi: 10.1111/j.1472765X.2010.03000.X

39. Lima LM, Dos Santos JP, Casagrande DR, Avila CLS, Lara MS, Bernardes TF. 2017. Lining bunker walls with oxygen barrier film reduces nutrient losses in corn silages. J Dairy Sci 100: 4565-4573. doi: 10.3168/jds.2016-12129

40. McEniry J, O'Kiely P, Clipson NJ, Forristal PD, Doyle EM. 2008. Bacterial community dynamics during the ensilage of wilted grass. J Appl Microbiol 105: 359-371. doi: 10.1111/j.1365-2672.2008.03802.x

41. Morales R. 2007. Las paredes celulares de levadura de Saccharomyces cerevisiae: un aditivo natural capaz de mejorar la productividad y salud del pollo de engorde. Tesis Doctoral. Barcelona, España: Universitat Autònoma de Barcelona. $261 \mathrm{p}$.

42. Muck RE. 2010. Silage microbiology and its control through additives. Rev Bras Zootecn 39: 183-191.

43. Muck RE, Nadeau EMG, McAllister TA, Contreras-Govea FE, Santos MC, Kung LJ. 2018. Silage review: recent advances and future uses of silage additives. J Dairy Sci 101: 3980-4000. doi: 10.3168/jds.2017-13839

44. Nkosi BD, Meeske R. 2010. Effects of whey and molasses as silage additives on potato hash silage quality and growth performance of lambs. S Afr J Anim Sci 40: 229-237.

45. Noblet J, Perez JM. 1993. Prediction of digestibility of nutrients and energy values of pig diets from chemical analysis. J Anim Sci 71: 3389-3398. doi: 10.2527/ $1993.71123389 \mathrm{x}$ 
46. Nout MJR, Bouwmeester HM, Haaksma J, Van Dijk H. 1993. Fungal growth in silages of sugarbeet press pulp and maize. J Agr Sci 121: 323-326.

47. [NRC] National Research Council. 2012. Nutrient requirements of swine. $11^{\text {th }}$ ed. Washington DC, USA: National Academies Press. p 400.

48. Odenigbo AM, Asumugha VU, Ubbor $S$, Ngadi M. 2013. In vitro starch digestibility of plantain and cooking-banana at ripe and unripe stages. Int Food Res J 20: 3027-3031.

49. Ogiy S, Chen Y, Pasvolsky R, Weinberg ZG, Moshe M. 2015. High resolution melt analysis to confirm the establishment of Lactobacillus plantarum and Enterococcus faecium from silage inoculants during ensiling of wheat. Grassl Sci 62: 29-36. doi: 10.1111/ grs. 12102

50. Parra R. 2010. Review. Bacterias ácido lácticas: papel funcional en los alimentos. Fac Cienc Agropec 8: 93-105.

51. Plumed-Ferrer C, Kivela I, Hyvonen $P$, Von Wright A. 2005. Survival, growth and persistence under farm conditions of a Lactobacillus plantarum strain inoculated into liquid pig feed. J Appl Microbiol 99: 851-858. doi: 10.1111/ j.1365-2672.2005.02666.x

52. Plumed-Ferrer C, Von Wright A. 2009. Fermented pig liquid feed: nutritional, safety and regulatory aspects. J Appl Microbiol 106: 351-368. doi: 10.1111/ j.1365-2672.2008.03938.x.

53. Ramírez, J, Ulloa P, Velázquez M, Ulloa J, Romero F. 2011. Bacterias lácticas: importancia en alimentos y sus efectos en la salud. Revista Fuente 7: 1-16.

54. Reich LJ, Kung L. 2010. Effects of combining Lactobacillus buchneri 40788 with various lactic acid bacteria on the fermentation and aerobic stability of corn silage. Anim Feed Sci Tech 159: 105-109. doi: 10.1016/j.anifeedsci.2010.06 .002

55. Sakomura N, Rostagno H. 2007. Métodos de pesquisa em nutrição de monogástricos. Jaboticabal: FUNEP. 283 p.
56. Schmidt RJ, Kung L. 2010. The effects of Lactobacillus buchneri with or without a homolactic bacterium on the fermentation and aerobic stability of corn silage made at different locations. J Dairy Sci 93: 1616-1624. doi: 10.3168/jds.20092555

57. Scholten RHJ, Van der PeetSchwering CMC, Den Hartog LA, Balk M, Schrama JW, Verstegen MWA. 2002. Fermented wheat in liquid diets: effects on gastrointestinal characteristics in weanling piglets. J Anim Sci 80: 1179-1186. doi: 10.2527/2002.805$1179 \mathrm{x}$

58. Scholten RM, Rijnen JA, Schrama JW, Boer H, Vesseur PC, den Hartog, $L A$, Van der Peet-Schwering CM, et al. 2001. Fermentation of liquid coproducts and liquid compound diets: Part 1. Effects on chemical composition during a 6-day storage period. J Anim Physiol An N 85: 111-123. doi: 10.1046/ j.1439-0396.2001.00309.x

59. Shirai K, Guerrero I, Lara P. 1996. Bacterias lácticas en alimentos fermentados. Ciencia 47: 125-137.

60. Silva MAA, Furlan AC, Moreira I, Paiano D, Scherer C, Martins EN. 2008. Nutritional evaluation and performance of cassava root silage with or without whole soybean in for nursery piglets. Rev Bras Zootecn 37: 14411449. doi: 10.1590/S1516-35982008000800015

61. Silva MAA, Furlan AC, Moreira I, Toledo JB, Carvalho PLO, Scapinello $C$. 2010. Nutritional evaluation and performance of cassava root silage with or without whole soybean in swine diets. Acta Sci Anim Sci 32: 155-161.

62. Song S, Bae DW, Lim K, Griffiths MW, Oh S. 2014. Cold stress improves the ability of Lactobacillus plantarum 167 to survive freezing. Int J Food Microbiol 191: 135-143. doi: 10.1016/ j.ijfoodmicro.2014.09.017

63. Suárez-Machín C, Garrido-Carralero N, Guevara-Rodríguez C. 2016. Levadura Saccharomyces cerevisiae y la 
producción de alcohol. Revisión bibliográfica. ICIDCA 50: 20-28.

64. Taysayavong L. 2018. Impact of fermentation on the nutritive value of cassava root pulp and soybean pulp as a feed for growing pigs in Lao PDR. Tesis Doctoral. Uppsala, Sweden: Swedish University of Agricultural Sciences. $78 \mathrm{p}$.

65. Van Winsen RL, Lipman LJA, Biesterveld S, Urlings BAP, Snijders JMA, Van Knapen F. 2001. Mechanism of Salmonella reduction in fermented pig feed. J Sci Food Agr 81: 342-346.

66. Wang J, Ji HF, Wang SX, Zhang DY, Liu H, Shan DC, Wang YM. 2012. Lactobacillus plantarum ZLP001: In vitro assessment of antioxidant capacity and effect on growth performance and antioxidant status in weaning piglets. Asian Austral J Anim 25: 1153-1158. doi: 10.5713/ajas.2012.12079

67. Zahiroddini H, Baah J, Absalom W, Mcallister TA. 2004. Effect of an inoculant and hydrolytic enzymes on fermentation and nutritive value of whole crop barley silage. Anim Feed Sci Tech 117: 317-330. doi: 10.1016/j.anifeedsci.2004.08.013

68. Zhang Y, Zhu L, Dong P, Liang R, Mao Y, Qiu S, Luo X. 2018. Bioprotective potential of lactic acid bacteria: Effect of Lactobacillus sakei and Lactobacillus curvatus on changes of the microbial community in vacuum packaged chilled beef. Asian Austral J Anim 31: 585-594. doi: 10.5713/ajas.17.0540 